\title{
A BRIEF INTERVENTION PROGRAMME FOR OUTPATIENT TREATMENT FOR METHAMPHETAMINE USERS
}

\author{
Michal Růžička, Edmund Wittmann
}

\begin{abstract}
This work aims to inform the reader about a new individual ambulatory therapy for people addicted to stimulant drugs (cocaine, crack and/or pervitin (methamphetamine)). The new methodology called A Brief Intervention Programme is used in Great Britain for users of cocaine and crack. Based on the cooperation of P-Centrum, Olomouc and the British company Foundation 66, which developed the methodology mentioned, it has been adapted for the pervitin (methamphetamine) users. The transformation followed after the programme had been applied and evaluated for a year and resulted in a new methodology called: Brief Intervention Programme for Pervitin Users. Advantages of this new methodology can be seen in its easy applicability and relatively short term duration. The methodology is based on the concept of cognitive behavioural therapy and education of the client leading to understanding the principles of his/her addiction. The work also intends to inform the reader about the transformation process of the methodology.

The main reason for placement of this article into E-pedagogium journal is the educational potencial of the therapeutical programme. We can say that the programme is partially educative and partially therapeutical. Because of this content, it is suitable as the work instrument for special education teachers and social workers who work with problematic drug users.
\end{abstract}

\section{Key words}

The brief intervention programme, cocaine, crack, pervitin (methamphetamine), treatment methodology, P-centrum.

\section{New method to work with clients addicted to pervitin}

The scope of ambulatory consulting therapeutic work largely involves work with pervitin (methamphetamine) clients. A range of those clients are motivated to solve their troubled situation, however, not behind the walls of a psychiatric clinic or residential community centre. When searching for new resources for such clients we (P-Centrum, Olomouc) got interested in 
the British method described below and started a close cooperation with the company Foundation 66, where the methodology was developed. As a result of our mutual work we can now make use of a new methodology, which helps pervitin clients on their way to abstinence.

Brief intervention programme for cocaine and crack users and its transformation into the pervitin programme

The father of the Brief Intervention Programme is Aidan Gray, who has developed two programmes for cocaine and crack users. For more information see the following website: http://www.pcentrum.cz/index.php?option=com content\&view $=$ article \&id=7\&Itemid= 13 .

The programme outlines two alternatives of work with the client. The first programme, i.e. the Threshold 2-week Programme is designed for those clients who do not want to stop using and are not motivated to abstain. It consists of two sessions, which concentrate on important information that the client should be aware of. You can say it involves important harm reduction information specific for pervitin. If you manage to arouse an interest in the client to work on, the client may continue in the other 12-week programme.

The second programme, i.e. the 12-week Brief Intervention Programme is destined for those clients who want to work towards abstinence. It consists of 12 keywork sessions. An outline of the programme is included in Appendix No. 1 . This programme is specific in that it runs simultaneously with the main therapeutical programme. It is basically 12 keywork sessions on top of the common ambulatory meetings.

Since $1^{\text {st }}$ January 2010 the above stated programmes have been applied by a working team of 7 therapists specifically trained for the methodology by its author. The therapists went through the programme with clients (pervitin users) and recorded their experience in case histories (100 case histories). These case histories and work experiences themselves were evaluated at regular meetings, where Dr. Miroslav Charvát from the Department of Psychology of the Philosophical Faculty, Palacký University, Olomouc was the main evaluator. For further information, processes and presentations of the methodology see the article. More detailed information on methodology was published elsewhere (Růžička, 2010).

After a year's experience applying and evaluating the programme, we gave it a new form so that it could be efficient and attractive to Czech clients. 


\section{New version of the Brief Intervention Programme for Pervitin Users}

One of the most frequent questions asked when evaluating the programme is whether it is suitable for all pervitin users. We have found that the programme requires a certain level of the client's cognitive skills. A large part of the programme has an educational character and therefore it is necessary for the client to be able to understand individual aspects of the programme. That is why we have introduced a 'zero' session in the programme consisting of a so-called "explorative interview". This interview results either in the client's motivation for the programme or in a choice of a different form of work.

Another frequently discussed question was what reasons there were for the existence of two programmes. Having evaluated our experience we eventually drafted a single programme, making use of the experience and knowledge gained from both of the previous ones. Provided that the client does not decide to abstain, the therapy is terminated after a basic education consisting of understanding the cycles and patterns of use, harm reduction and how pervitin works.

In the original version of the programme there were 12 modules that the client gradually went through and achieved their objectives. A common therapy went alongside this programme. This alternative was finally judged as a very demanding one due to two meetings with a client per week. In case of ambulatory work on condition that the client was looking for a job or working already, it was time-consuming. For this reason we connected those programme modules with a rather educational content to therapy work. This connection resulted in so-called "therapy-intervention programme", whose length does not last more than 60 minutes a week. The whole methodology consists of four parts. Firstly, there are so-called 'solid modules', in which we mainly analyze the client's problem in reference to his/her understanding of how pervitin works in brain. Secondly, there are so-called 'free modules', which have a form of optional themes adapted to the client's current needs (i.e. health hazards, relation of drug use to crime, after-care etc.). Thirdly, there are information handouts, i.e. kind of educational facts for the client. Finally, there are worksheets, into which the clients writes down information about the work process, possibly partial results of his/her work.

As it has already been mentioned, the brief intervention programme is based on principles of cognitive-behavioural therapy. We worked in the spirit of this therapy approach as well. The key to our work is seen in making 
functional analysis of the client's situation before we advance to the further activities and programme modules. To draft the functional analysis is sometimes a very difficult job, in which the worksheet Cycles of use is of great help. You may obtain a better view of this worksheet by reading Appendix No. 2, where a detailed scheme describes how to work with the worksheet. The therapist completes the worksheet together with the client and subsequently they refer it to other cases and situations. The last part is formed by worksheets, into which the client fills in the process or partial outcomes of his or her work. The whole duration of the programme is then 12 to 15 weeks, depending on the needs and possibilities of the client.

The original programme included information handouts. They were supposed to inform the client about the issues that were being solved during the therapy. As we were evaluating these materials we were gradually reducing the amount of information comprised in these handouts in order to make their contents as short as possible, yet still understandable. The handouts are in the form of educational tools, which aim to inform the client about certain themes. For more information see the sample of the handout in Appendix 3.

Thanks to shortening the handouts we have managed to motivate the clients to read them and we also make them think about the issues towards themselves. Since $1^{\text {st }}$ September, 2011 we have been working with a new methodology that was modified as mentioned and got a name Pervitin II. We continue recording clients' case histories, which will be subsequently evaluated in the Final Draft of the programme. The whole text will be available at www.p-centrum.cz in the second half of 2012.

\section{Conclusion}

The work intends to acquaint the reader with the transformation process of the methodology developed in Great Britain with the aim of adapting it for the local stimulant drug users. It has turned out that mere translation is not enough, nor is the modification according to specifics of the target drug (i.e. pervitin). Thanks to evaluation of the work with clients (pervitin users) we have understood an urgent need of involving social, cultural and regional aspects. We are trying to make these specific aspects become part of the methodology during the transformation process. We recommend the reader to see the above mentioned website, where both the original and translated version of the methodology is available, possibly to get in touch with us if you have further questions. 


\title{
Czech/English equivalent for the grant purposes
}

OP LZZ

Název projektu: Dokážu to?

Ćíslo projektu:(1.04/5.101/12.00005)

\section{HRE OP-CZ}

Project Name: Can I do it?

Project Number: (1.04/5.101/12.00005).

\section{Bibliography}

Gray, A. (2006). Final draft crack/cocaine Brief intervention programme (CNTA/ COCA/Rugby House.

Garris, A., \& Wightman, M., \& William, M., \& Kenan, R. (1999). Dopamine Not Brain Pleasure Source Paul University of North Carolina - Chapel Hill.

Orders, A., \& Gray, A. (2002). Crack and Cocaine: Good Practice Guidelines for Drug Treatment and Trstiny. Taegtmeyer, Commissioned by London Probation Service.

Růžička, M.. (2010). Krátký intervenční program pro ambulantní léčbu osob závislých na stimulantech. Adiktologie, 10(1), 64-67 ISBN 1213-3841.

Washton, A. (1989). Cocaine Addiction: Treatment, Recovery and Relapse Prevention Norton.

\section{Author's profile}

The Author works as a therapist in P-Centrum Olomouc, where he also works as the guarantee of ambulatory work. Further on, the author works as a University teacher at the Department of Special Education (The Faculty of Education, Palacký University, Olomouc).

\author{
Contact \\ Mgr. Michal Růžička, Ph.D. \\ workplace: \\ P-Centrum \\ Lafayettova 9 \\ 77140 Olomouc \\ address: \\ Mozartova 57 \\ 77140 Olomouc \\ Czech Republic \\ e-mail: m.ruzicka@email.cz \\ telephone: +420720447119
}




\section{Appendix No. 1: 12- week Programme Outline}

\section{Keywork Connections Flowcharts}

\section{Connections}

Throughout the programme it is important for workers to identify themes and help the client make connections. This will help client build up their awareness of recurring situations and develop action plans for possibly dangerous situations. There are many different themes and the simple examples below follow some connections through the programme:

\begin{tabular}{|c|c|}
\hline $\begin{array}{l}\text { 1. Intro \& } 12 \text { week goals } \\
\text { Client identifies working towards getting } \\
\text { her children back as a goal. }\end{array}$ & $\begin{array}{l}\text { Keywork session } \\
\text { Contact developed with Social Services, } \\
\text { high score of } 102 \text { on CMF, lapse work. }\end{array}$ \\
\hline $\begin{array}{l}\text { 2. How crack } \& \text { cocaine work } \\
\text { Depression is strongly related to by the } \\
\text { client in this session. }\end{array}$ & $\begin{array}{c}\text { Keywork session } \\
\text { Further work on depression, score of } \mathbf{8 6} \\
\text { on CMF, continued lapse work. }\end{array}$ \\
\hline 3. Health implications & Keywork session \\
\hline $\begin{array}{l}\text { 4. Closing doors on scoring } \\
\text { Money, other users, areas and dealers all } \\
\text { connected with her sex work. }\end{array}$ & $\begin{array}{l}\text { Keywork session } \\
\text { Further work on / support with leaving sex } \\
\text { industry, score of } 75 \text { on CMF. }\end{array}$ \\
\hline $\begin{array}{c}\text { 5. Cycles of use } \\
\text { Feelings thoughts of depression, guilt \& } \\
\text { worthlessness key factors in cycle of use. }\end{array}$ & $\begin{array}{l}\text { Keywork session } \\
\text { Support work around feelings / thoughts, } \\
\text { score of } 73 \text { on CMF. Lapse work. }\end{array}$ \\
\hline $\begin{array}{l}\text { 6. Patterns of using } \\
\text { Feelings (guilt, depression), how getting } \\
\text { money \& areas all major patterns. }\end{array}$ & $\begin{array}{l}\text { Keywork session } \\
\text { Links being made on thoughts / feelings } \\
\text { and sex work, score of } 69 \text { on CMF. }\end{array}$ \\
\hline $\begin{array}{l}\text { 7. Understanding triggers } \\
\text { Feelings, how getting money and areas are all } \\
\text { prime triggers for her. }\end{array}$ & $\begin{array}{c}\text { Keywork session } \\
\text { Better understanding of links. } 1^{\text {st }} \text { week } \\
\text { drug free. Score of } 53 \text { on CMF. }\end{array}$ \\
\hline 8. Understanding cravings & $\begin{array}{l}\text { Keywork session } \\
\text { Lapse due to review letter from Social } \\
\text { Services, Score of } 74 \text { on CMF. }\end{array}$ \\
\hline 9. Euphoric recall & Keywork session \\
\hline 10. Connections with crime & Keywork session \\
\hline $\begin{array}{l}\text { 11. Dangerous situations } \\
\text { Case review for children soon, feelings of } \\
\text { guilt / depression very strong. }\end{array}$ & $\begin{array}{l}\text { Keywork session } \\
\text { Action plan / support networks put in } \\
\text { place for review. Score of } \mathbf{5 6} \text { on CMF. }\end{array}$ \\
\hline 12. After care and support & Keywork session \\
\hline
\end{tabular}




\section{Craving:}

Thinking: High expectation of reward, good times only, blinkered, one track mind, focus usually only upon the drug and what it will be like or what good things are associated with its use.
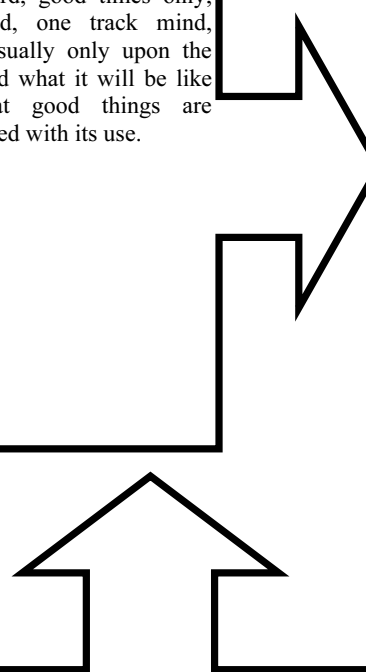

Recovery: Some of the feelings of the 'crash' have worn off. May have slept and eaten food or even had a long period of recovery. Physically feeling better.

Thinking: Feelings of depression may still be strong, depending on whether a daily or bingeing pattern is being followed (depression can lead to use again). Sometimes feeling more in control, not so bad leaving the client open to cue triggers and cravings again.
Drug Use: Initial quick 'high' achieved, though is for short time, leading to repeat use to try and gain the high again. Other drugs may be used such as alcohol or heroin increasing the high and compulsion to use. Increased levels of adrenaline.

Thinking: Anxiety and paranoia may be high changing the way they think.

Environment can have great effect on thinking. Chasing the high very strong.

Feel out of control.

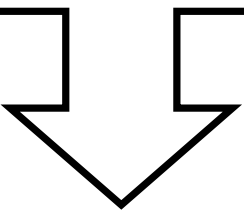

Comedown: Session has finished or the drugs have run out. High levels of adrenaline leading to the feeling of being 'prang' or 'wired'. Depressant drugs used to try and level things out and lesson the feelings.

Thinking: High levels of remorse, paranoia, anxiety and depression. Regret and feelings of it not being worth it. Just want to go to sleep to get rid of the thoughts and feelings.

(The appendix No. 1 and 2. are from: the original programme Gray, A. (2006). Final draft crack/cocaine Brief intervention programme CNTA/ COCA/Rugby House.) 
Appendix No. 3: Example of a handout (Handout: How pervitin works)

\section{Module title: How pervitin works}

\section{Objectives}

This module explains how pervitin works in the brain and helps the client understand how the motivation for change gets transformed

1. To expand the client's knowledge of addiction in the brain (neurology of addiction)

2. To develop the client's understanding of pervitin

3. To build trust with the worker/service staff

4. To lay the foundation for forthcoming sessions

\section{Guidelines}

Before starting the session, therapists should refer to the information that has been gathered by the Comprehensive Assessment paying particular attention to:

- Amounts of pervitin used

- Routes of use

- How it is supporting the habit

The Comprehensive Assessment will give you information that can be used in this session and enable you to personalize how pervitin is working with this client.

Reward system in the brain - a regulatory mechanism, which provides things necessary for survival and reproduction, and creates feelings of well-being. Situations, processes and stimuli in the environment that are necessary for survival of an individual (species) are connected with feelings of pleasure (reward) in order to be likely to happen again and thus the probability of survival would increase.

\section{Biologically natural sources of reward:}

$>$ food (survival of an individual)

$>$ various forms and levels of social relations (survival in a group)

$>$ sex (survival of a species)

The reward system ensures motivation for an individual to behave in such a way to gain the natural reward and survive. The key functional and anatomic reward system structure is considered to be the brain part nucleus accunbens, where the reward system increases the release of dopamine. 
The reward system cannot be seen as an isolated centre. You had better picture it as a brain network, which is intensively and mutually interconnected as well as abundantly connected with other close function centres.

The reward system is closely connected with the function of memory, stress system and system responsible for compulsive repetition of activities.

The reward system is closely connected with the function of memory. The whole picture of the situation when reward was gained is recorded in the memory. Then the pictures are arranged in brain according to their importance and difficulty to obtain, by means of which an individual gains a palette of experience. A man remembers an efficient strategy of behaviour leading towards successful achievement of pleasure by current stimuli or those set aside.

Stress systems are also in close connection with the reward system. They work to avoid situations which might lead to great discomfort or danger. Unpleasant stimuli causing feelings of discomfort are in cooperation with memory system associated with a negative psychic process, e.g. an emotion.

Pervitin - an artificial source of reward. Differences in comparison with natural sources of reward are as follows:

$>$ To achieve the reward is faster and easier

$>$ The reward is much more powerful

$>$ There are no mechanisms to stop accepting artificial rewards

"Pampered brain" - a change after long-term, regular and intensive pervitin use:

$>$ It wants a fast reward straight away and it does not want complicated strategies to achieve it

$>$ Stress is solved by drug use

$>$ Memory is filled at different levels by information how to gain drug reward

$>$ Systems that are connected with complicated long-term strategies are ceasing to be used

\section{Pervitin - how it works}

Pervitin does not cause physical dependence; however, it creates a very strong psychological dependence. Pervitin works by triggering the release of chemicals that are already present in the body. These chemicals are part of the body's response to danger (adrenaline) and pleasure (dopamine). 
Pervitin changes the way of communication between the nerve cells (neurones). Nerve cells in the brain normally send messages to each other using chemicals called neurotransmitters. These neurotransmitters are transferred between two cells in so-called "synapses" (connection of two neurones). Neurotransmitters fire across a gap between each cell and attach onto receptor sites. Once the message has been received the transporter cell then collects up the neurotransmitters so that the levels in these chemicals remain balanced.

A nerve cell and its communication with another nerve cell

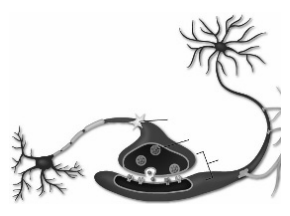

Dopamine is a neurotransmitter that helps to control the feelings of pleasure and is repeatedly released by the use of pervitin. At the same time the transporter cell is blocked and does not return this neurotransmitter.

This results in a significant increase in the concentration of dopamine in synapses.

This leads to the extended feelings of pleasure that are experienced when taking pervitin and also ultimately leads to the 'downs' experienced by causing depletion in these chemicals.

Imagine getting a brand new credit card, you have extended spending power for a period of time, you have fun and then the bill arrives through your letterbox.

Pervitin works with the sympathetic part of the nervous system, which is concerned with outside stimulus such danger and anticipation. The 'Fight and Flight' response is part of this and releases adrenalin and stress hormones into the body.

Adrenaline is released from adrenal glands as part of body's response to danger or excitement. It alerts senses and enables the body to work at full volume. It does so by:

- Increasing heart rate - It increases the speed of which oxygen gets into muscles

- Increasing breathing rate - It increases the amount of oxygen in the blood stream

- Sweating - It prevents the body from getting too hot

- Shaking - This is due to the increased energy ready for release 
- Butterflies in the stomach, urge to go to the toilet - This is due to blood leaving the stomach and being diverted to muscles

Users may interpret the above symptoms as the feelings they get when craving pervitin or are just about to score. When they do use pervitin, they are again releasing adrenaline.

Persistent release of adrenaline caused by pervitin use can lead to decreased need for sleep; loss of appetite; visual and auditory hallucinations; memory, perception and concentration disorders; anxiety and paranoia, see toxic psychosis.

Toxic psychosis manifests itself by auditory hallucinations and hallucinations of other senses (visual hallucinations appear only rarely). The affected person is very touchy as though being permanently chased. They have a feeling that the whole world has conspired against them and that their friends gossip or at least talk about them. They are uneasy or on the contrary rigid. They are anxious and experience abnormal emotions, which do not have a real basis. They fight a thought-out attack or run away from something that is existent in their minds only.

Metaphor: a flying balloon, a pot of pleasure substance that is being exhausted. 